D) Check for updates

Cite this: J. Mater. Chem. B, 2021 9, 2918

Received 6th October 2020,

Accepted 12th March 2021

DOI: 10.1039/d0tb02379e

rsc.li/materials-b

\section{Bioinspired and eco-friendly high efficacy cinnamaldehyde antibacterial surfaces $\uparrow$}

\author{
Harrison J. Cox, ${ }^{a}$ Jing Li, ${ }^{a}$ Preety Saini, ${ }^{a}$ Joy R. Paterson, ${ }^{b}$ Gary J. Sharples ${ }^{b}$ and \\ Jas Pal S. Badyal (D) *a
}

\begin{abstract}
Antimicrobial essential oils are incorporated into mussel-inspired and natural plant polyphenol coatings as part of a single-step fabrication process. Polydopamine-cinnamaldehyde, polyethyleneimine-cinnamaldehyde, and tannic acid-cinnamaldehyde coatings exhibit strong antibacterial activities against both Gram-negative Escherichia coli and Gram-positive Staphylococcus aureus (with the polydopamine- and tannic acid-based systems displaying $\log _{10}$ Reduction $=8$ ). Cinnamaldehyde impregnation into porous non-woven polypropylene cloth, polytetrafluoroethylene membrane, and knitted cotton cloth also gives rise to high levels of antibacterial activity $\left(\log _{10}\right.$ Reduction $=8$ ). No loss in antibacterial efficacy is observed for non-woven polypropylene cloth impregnated with cinnamaldehyde over 17 recycle tests.
\end{abstract}

\section{Introduction}

Production of polydopamine adhesive coatings via the autoxidation of dopamine in basic solution has been widely reported. ${ }^{1}$ These coatings readily adhere to a variety of substrate materials, including metals, plastics, and even low surface energy polytetrafluoroethylene. The catechol functionality of dopamine mimics the adhesive Mytilus edulis foot protein 5 (Mefp-5) found in mussels, which is capable of adhering to virtually any kind of surface. ${ }^{2,3}$ A related natural coating-forming phenolic compound is tannic acid-a plant polyphenol, derived from the nutgalls of Quercus and Sumac (Rhus) species, as well as the seed pods of Tara (Caesalpinia spinosa). ${ }^{4}$ Tannic acid also forms an adhesive polymeric coating under oxidising basic conditions, in a similar fashion to polydopamine. ${ }^{5}$ One potential issue associated with the use of polydopamine coatings is the relatively high cost of the dopamine hydrochloride precursor, hence tannic acid is considered as a viable alternative for large scale applications. ${ }^{5}$

Polydopamine alone does not exhibit strong antibacterial activity, and so much research has been conducted into the post-functionalization of polydopamine coatings. Examples include the attachment of silver, ${ }^{6-8}$ copper, ${ }^{9,10}$ quaternary ammonium compounds, ${ }^{11,12}$ zwitterionic compounds, ${ }^{13}$ chlorhexidine, ${ }^{14}$ antibiotics, ${ }^{15}$ peptides,${ }^{16}$ or enzymes. ${ }^{17}$ Many of these antibacterial polydopamine-based coatings are

\footnotetext{
${ }^{a}$ Department of Chemistry, Durham University, Durham DH1 3LE, England, UK. E-mail:j.p.badyal@durham.ac.uk

${ }^{b}$ Department of Biosciences, Durham University, Durham DH1 3LE, England, UK $\dagger$ Electronic supplementary information (ESI) available. See DOI: 10.1039/ dotb02379e
}

unsuitable for industrial scale-up due to their inherent multi-step syntheses, and often prohibitively long reaction times. Also, there have been reports of combining polydopamine with an antibacterial agent for 'one-pot' (single-step) hybrid coatings; for example polydopamine-silver and polydopaminecopper. ${ }^{18,19}$ In the case of tannic acid coatings, again, methods reported rely upon additives such as silver ${ }^{20,21}$ or $\operatorname{copper}^{21,22}$ to impart antibacterial activity. However, antimicrobials such as silver and copper have inherent drawbacks, chiefly their relatively high cost compared to organic compounds. Also, there exists concern about their environmental impacts, including toxicity to plants and aquatic organisms (as well as a lack of knowledge concerning toxicity in humans). ${ }^{23,24}$ The emergence of antimicrobial resistance is another issue surrounding metalbased antibacterial materials. ${ }^{25}$

Polyethyleneimine polymer comprises repeat units containing two methylene carbons and an amine centre. The ratio of primary to secondary to tertiary amines is typically $1: 1: 1$ in commercially available products. ${ }^{26}$ Polyethyleneimine is not particularly antibacterial on its own, but its large number of amine functionalities can be reacted with alkyl halides to yield quaternary ammonium groups which display antibacterial activities. ${ }^{27}$

Naturally-occurring plant-derived essential oil compounds are also known for their antimicrobial benefits. ${ }^{28}$ Cinnamaldehyde, a major component of cinnamon bark oil, ${ }^{29,30}$ is reported to show antibacterial, ${ }^{31,32}$ antifungal, ${ }^{33}$ antiparasitic, ${ }^{34}$ insecticidal, ${ }^{35}$ antiviral, ${ }^{36}$ anticancer, ${ }^{37}$ anti-diabetic ${ }^{38}$ and pro-wound healing ${ }^{39}$ properties. Cinnamaldehyde is antibacterial through multiple mechanisms which vary according to the pathogen. ${ }^{40}$ The mode of action of cinnamaldehyde against Escherichia coli and Staphylococcus aureus is reported to involve interaction of cinnamaldehyde with the cell membrane, which results in an 
increase in the cell permeability, changes to cell morphology, and damaging of cell membrane integrity, ultimately leading to cell lysis and cytoplasmic content leakage. ${ }^{41-43}$ It has also been shown that cinnamaldehyde can cause oxidative damage to E. coli cells. ${ }^{44}$ Many of the reported cinnamaldehyde-based antibacterial materials and surfaces involve the blending of cinnamaldehyde with a polymer (either as a melt or in solution) followed by casting into a film. Some of the polymers used include: polyvinyl alcohol, ${ }^{45}$ polypropylene, ${ }^{46}$ polystyrene, ${ }^{47}$ cellulose, ${ }^{48}$ and chitosan. ${ }^{49}$ Such cinnamaldehyde-containing films are effective at stopping bacterial or mould growth on, for example, various foodstuffs-including beef, ${ }^{45}$ chicken and ham ${ }^{50}$ vegetables (radish, broccoli, and alfalfa) sprouts, ${ }^{51}$ and bakery products. ${ }^{52}$ However, manufacture of such essential oil impregnated polymer films requires costly organic solvents ${ }^{53}$ or involves application of heat, which can be detrimental due to degradation or volatilization of the bioactive compound. ${ }^{54}$ Furthermore, much of the cinnamaldehyde content within the bulk material is inaccessible to the external environment (bacteria).

In this article, single-step dip-coating deposition of cinnamaldehyde-containing antibacterial surface layers is described. Dopamine is polymerized in the presence of an aqueous solution containing tris(hydroxymethyl)aminomethane and cinnamaldehyde, Scheme 1. Analogous antibacterial coatings are prepared by combining polyethyleneimine or tannic acid with cinnamaldehyde. Additionally, cinnamaldehyde is impregnated into a range of porous materials, including non-woven polypropylene cloth, polytetrafluoroethylene membrane, and knitted cotton, via simple dip-coating, to achieve high levels of antibacterial activity over extended recycling. Each of these approaches is inspired by the presence of bioactive compounds often found in plant epicuticular wax layers and essential oil glands located at the surfaces of leaves and citrus peel. ${ }^{55-57}$

\section{Experimental}

\section{Coating preparation}

Polyethylene terephthalate film (PET, capacitor grade, $0.10 \mathrm{~mm}$ thickness, Lawson-Mardon Ltd), non-woven polypropylene cloth $(0.41 \mathrm{~mm}$ thick, $22.7 \pm 4.4 \mu \mathrm{m}$ fibre diameter, with dimpled structure $0.68 \pm 0.16 \mathrm{~mm}$ separation, spunbond, $70 \mathrm{~g} \mathrm{~m}^{-2}$, Avoca Technical Ltd), polytetrafluoroethylene microporous membrane (PTFE, Type $3 \mathrm{~V}$, surface area $5.6 \mathrm{~m}^{2}$, Mupor Ltd), and knitted cotton fabric (WarwickEquest Ltd) were cut into $15 \mathrm{~mm} \times 15 \mathrm{~mm}$ pieces and used as substrates for coating.

Polydopamine-only reference coating solutions were prepared using dopamine hydrochloride (30 mg, 99\%, Alfa Aesar brand, Fisher Scientific UK Ltd) dissolved in aqueous solution of tris(hydroxymethyl)aminomethane buffer $(10 \mathrm{ml}$, 25 mM, pH 8.5, 99.8\%, Acros Organics brand, Fisher Scientific UK Ltd) in a glass vial. ${ }^{1}$ Substrates were immediately placed into the vial, the lid closed, and the vials then shaken for $24 \mathrm{~h}$ at $20{ }^{\circ} \mathrm{C}$ using an orbital shaker (model Vibrax VXR, IKA Ltd). Subsequently the substrates were removed and washed with

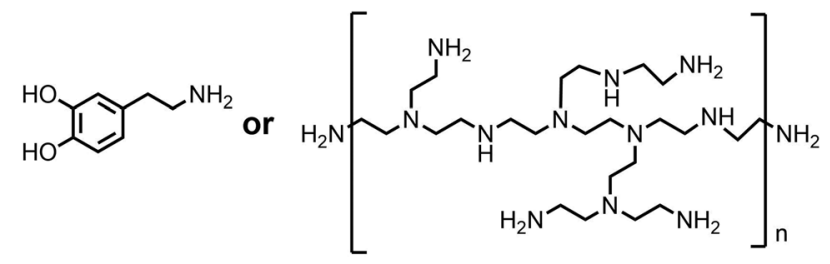

\section{Dopamine Polyethyleneimine}

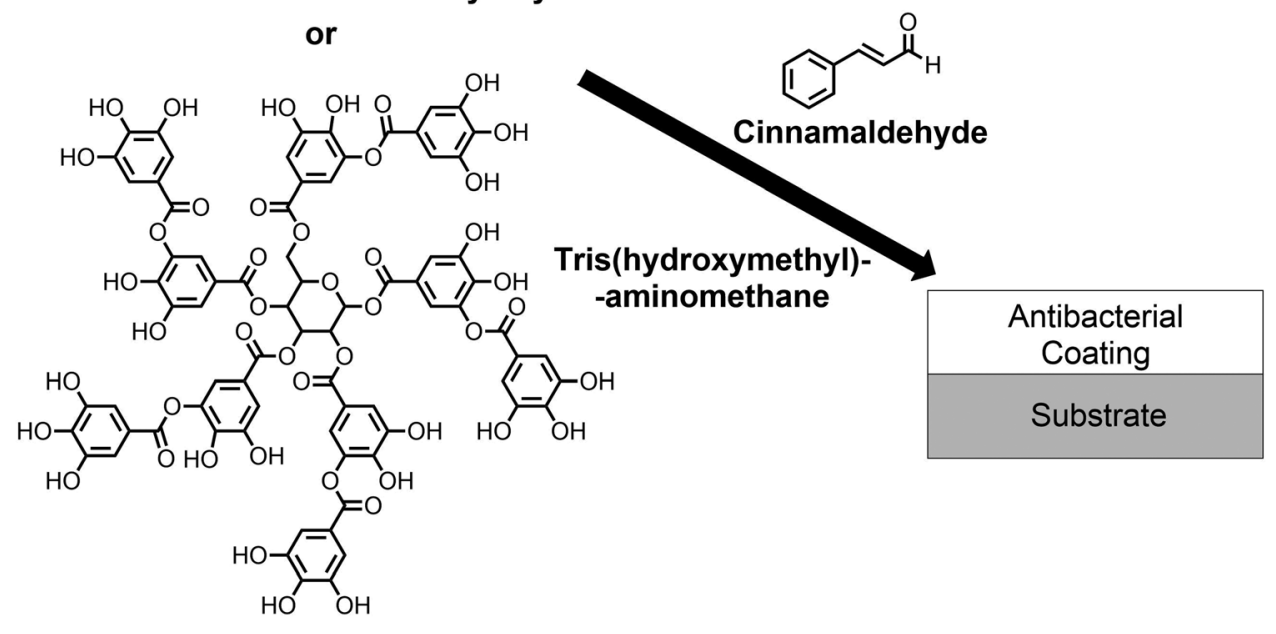

Tannic Acid

Scheme 1 Deposition of polydopamine-cinnamaldehyde, polyethyleneimine-cinnamaldehyde, and tannic acid-cinnamaldehyde antibacterial coatings. 
ultrapure water (Type 1, produced by water purification system model Milli-Q Integral 3 Water Purification System, Millipore Ltd) for 5 min whilst shaking, and then placed on a glass slide to dry in air for at least $3 \mathrm{~h}$ at $20{ }^{\circ} \mathrm{C}$.

Cinnamaldehyde-only reference solutions were prepared by adding trans-cinnamaldehyde (150 $\mathrm{mg}$ equivalent to $15 \mathrm{mg} \mathrm{ml}^{-1}$ in final solution; 99\%, Acros Organics brand, Fisher Scientific UK Ltd) into a glass vial followed by $10 \mathrm{ml}$ of aqueous tris(hydroxymethyl)aminomethane buffer (25 mM, pH 8.5). Substrates were immediately placed into the vial, the lid closed, and the vials then shaken for $24 \mathrm{~h}$ at $20{ }^{\circ} \mathrm{C}$ using an orbital shaker. Subsequently the substrates were removed and washed with ultrapure water for 5 min whilst shaking, and then placed on a glass slide to dry in air for at least $3 \mathrm{~h}$ at $20{ }^{\circ} \mathrm{C}$.

Polydopamine-cinnamaldehyde coating solutions were prepared by mixing dopamine hydrochloride $(30 \mathrm{mg})$ and cinnamaldehyde $(150 \mathrm{mg})$ in a glass vial. Aqueous tris(hydroxymethyl)aminomethane buffer $(10 \mathrm{ml}, 25 \mathrm{mM}, \mathrm{pH} 8.5)$ was then added to the vial (i.e. equivalent to $3 \mathrm{mg} \mathrm{ml}^{-1}$ of dopamine hydrochloride, cinnamaldehyde at $15 \mathrm{mg} \mathrm{ml} \mathrm{ml}^{-1}$ solution, equivalent to a 1:5 mass ratio of dopamine hydrochloride to cinnamaldehyde and a 1:4.5 molar ratio of tris(hydroxymethyl)aminomethane to cinnamaldehyde). For polyethyleneimine-cinnamaldehyde coating, polyethyleneimine solution (2.0 g, 50 wt\% aqueous, MW 750000 Da, branched, SigmaAldrich Ltd) was diluted in $50 \mathrm{ml}$ of water to give a $20 \mathrm{mg} \mathrm{ml}^{-1}$ aqueous solution of polyethyleneimine. Cinnamaldehyde $(200 \mathrm{mg})$ and $10 \mathrm{ml}$ of the $20 \mathrm{mg} \mathrm{ml}^{-1}$ polyethyleneimine solution were then added to a vial. Control polyethyleneimine-only treated substrates were immersed in the $20 \mathrm{mg} \mathrm{ml}^{-1}$ aqueous solution of polyethyleneimine. Preparation of tannic acid-cinnamaldehyde coating solutions comprised mixing tannic acid (30 mg, SigmaAldrich Ltd) with cinnamaldehyde $(30 \mathrm{mg})$ in a glass vial. Aqueous tris(hydroxymethyl)aminomethane buffer $(10 \mathrm{ml}$, $25 \mathrm{mM}, \mathrm{pH}$ 8.5) was added to the vial (equivalent to both tannic acid and cinnamaldehyde at $3 \mathrm{mg} \mathrm{ml}^{-1}$ solution, and a 1:1 weight ratio of tannic acid to cinnamaldehyde)-absence of tris(hydroxymethyl)aminomethane did not lead to complete coating formation. Tannic acid-only coating solutions were similarly prepared by excluding cinnamaldehyde in the procedure. For each of the aforementioned coating solutions, substrates were immediately placed into the vial, the lid closed, and the vials shaken for $24 \mathrm{~h}$ at $20{ }^{\circ} \mathrm{C}$ using an orbital shaker. Subsequently the substrates were removed and washed with ultrapure water for $5 \mathrm{~min}$ whilst shaking, and then placed on a glass slide to dry in air for at least $3 \mathrm{~h}$ at $20{ }^{\circ} \mathrm{C}$.

Phenethylamine-cinnamaldehyde product was prepared by dissolving phenethylamine $(0.10 \mathrm{ml}, 0.794 \mathrm{mmol}, 99 \%$, SigmaAldrich Ltd) and cinnamaldehyde $(0.10 \mathrm{ml}, 0.794 \mathrm{mmol})$ in methanol (10 ml, >95\%, Fisher Scientific UK Ltd) and allowing to react in a glass vial with the lid closed for $24 \mathrm{~h}$ at $20{ }^{\circ} \mathrm{C}$. The lid was then removed, and the methanol evaporated off at $20{ }^{\circ} \mathrm{C}$. The formed product was dried under vacuum and analysed.

Porous non-woven polypropylene cloth pieces were immersed into $10 \mathrm{ml}$ aqueous suspension of cinnamaldehyde
(15 $\mathrm{mg} \mathrm{ml}^{-1}$ ) and shaken for $24 \mathrm{~h}$ at $20{ }^{\circ} \mathrm{C}$; then removed, washed in ultrapure water for $5 \mathrm{~min}$, before finally drying in air for at least $3 \mathrm{~h}$ at $20{ }^{\circ} \mathrm{C}$. Polytetrafluoroethylene (PTFE) membrane and knitted cotton pieces were immersed into $10 \mathrm{ml}$ aqueous cinnamaldehyde suspension $\left(3 \mathrm{mg} \mathrm{ml}{ }^{-1}\right)$ and shaken for $24 \mathrm{~h}$ at $20{ }^{\circ} \mathrm{C}$, then removed, rinsed in ultrapure water for $5 \mathrm{~min}$, and placed on a glass slide to dry in air for a minimum of $3 \mathrm{~h}$ at $20{ }^{\circ} \mathrm{C}$. For all three porous materials, tris(hydroxymethyl)aminomethane was not included in the solutions.

\section{Coating characterization}

Infrared spectra were acquired using a FTIR spectrometer equipped with a liquid nitrogen cooled MCT detector (model Spectrum One, PerkinElmer Inc.). Spectra were collected at $4 \mathrm{~cm}^{-1}$ resolution across the $400-4000 \mathrm{~cm}^{-1}$ range and averaged over 265 scans. Attenuated total reflectance (ATR) infrared spectra of samples were acquired using a diamond ATR accessory (model Golden Gate, Graseby Specac Ltd). Reflection-absorption (RAIRS) measurements utilized a silicon substrate (Silicon Valley Microelectronics Inc.) in conjunction with a variable angle accessory (Graseby Specac Ltd) set at $66^{\circ}$ angle of incidence and fitted with a KRS-5 wire polarizer (to remove the s-polarized component). The infrared spectrum of dried polyethyleneimine was obtained from the supplied polyethyleneimine aqueous solution (following water removal in vacuo).

Ultraviolet-visible (UV-Vis) spectra were collected on a UV-Vis-NIR spectrophotometer (model Cary 5000, Agilent Technologies Inc.). Reference solution samples were analysed in quartz cuvettes with $1 \mathrm{~cm}$ path length. Coated samples were prepared by direct application onto quartz substrates (fused quartz plate, thickness $=1 \mathrm{~mm}$, UQG Ltd). For measuring cinnamaldehyde release into aqueous medium, each coated substrate was immersed into a glass jar containing $100 \mathrm{ml}$ of ultrapure water at $20{ }^{\circ} \mathrm{C}$, with the sample fully submersed below the water surface. $1 \mathrm{ml}$ aliquots were removed for UV-Vis analysis at various times. Each aliquot was further diluted with $9 \mathrm{ml}$ of water to give $\mathrm{a} \times 10^{-1}$ dilution. These diluted aliquots were placed into $1 \mathrm{~cm}$ path length quartz cuvettes and analysed using UV-Vis spectroscopy.

Atmospheric pressure solids analysis probe ionisation (ASAP) mass spectrometry was performed in positive ion mode (model Xevo QToF mass spectrometer, Waters Ltd, UK).

\section{Antibacterial testing}

Gram-negative Escherichia coli BW25113 (CGSC 7636; rrnB3 $\Delta l a c Z 4787$ hsdR514 $\Delta(\operatorname{araBAD}) 567 \Delta($ rhaBAD) $568 \quad r p h-1)$ and Gram-positive Staphylococcus aureus (FDA209P, an MSSA strain; ATCC 6538P) bacteria cultures were prepared using autoclaved (Autoclave Vario 1528, Dixons Ltd) Luria-Bertani broth media (LB; L3022, Sigma-Aldrich Ltd, $2 \% \mathrm{w} / \mathrm{v}$ in Milli-Q ${ }^{\circledR}$ grade water). A $5 \mathrm{ml}$ bacterial culture was grown from a single colony for $16 \mathrm{~h}$ at $37^{\circ} \mathrm{C}$, and then $50 \mu \mathrm{l}$ used to inoculate a sterile polystyrene cuvette (Catalogue No. 67.742, Sarstedt AG) containing $1 \mathrm{ml}$ of Luria-Bertani broth. The cuvette was covered with Parafilm 
(Cole-Parmer Ltd) and then placed inside a shaking incubator (model Stuart Orbital Incubator S1500, Cole-Parmer Ltd) set at $37{ }^{\circ} \mathrm{C}$ and $120 \mathrm{rpm}$ to allow the bacteria to grow until an optical density $\mathrm{OD}_{600 \mathrm{~nm}}=0.4$ was measured using a UV-Vis spectrophotometer (model Jenway 6300, Cole-Parmer Ltd) corresponding to the mid-log phase growth of bacteria.

Uncoated control samples were washed in absolute ethanol for $15 \mathrm{~min}$ and dried under vacuum in order to make sure they were sterile and clean. Antibacterial testing was performed within $24 \mathrm{~h}$ of making the coatings. Sterile microtubes $(1.5 \mathrm{ml}$, Sarstedt AG) were loaded with the uncoated or coated substrates. Next, $100 \mu \mathrm{l}$ of the prepared bacterial culture was pipetted onto each substrate placed aseptically inside a microtube so that the microorganisms could interact with one side of the surface. In practice, for non-porous substrates the liquid spread over the whole area of the sample, and for the porous substrates, the samples absorbed the liquid and so the entire $15 \mathrm{~mm} \times 15 \mathrm{~mm}$ area of the samples was permeated by the bacterial suspension. The microtube lid was closed, to prevent the sample drying out, and the tube placed horizontally on a sample tray and incubated (model Bacterial Incubator 250, LMS Ltd) without shaking for $4 \mathrm{~h}$ at $30^{\circ} \mathrm{C}$. Next, $900 \mu \mathrm{l}$ of autoclaved Luria-Bertani broth media was pipetted into each microtube and vortexed (model Vortex-Genie 2, Scientific Industries Inc.) in order to recover the bacteria as a 10 -fold dilution $\left(10^{-1}\right)$. Further ten-fold serial dilutions were undertaken to provide $10^{-2}$, $10^{-3}, 10^{-4}, 10^{-5}$ and $10^{-6}$ samples. Colony-forming unit (CFU) plate counting was performed by placing $10 \mu \mathrm{l}$ drops from each diluted sample $\left(10^{-1}\right.$ to $10^{-6}$ dilutions) onto autoclaved Luria-Bertani agar solid plates $\left(\right.$ EZMix $^{\mathrm{TM}}$ powder, dust free, fast dissolving fermentation medium, L7533, SigmaAldrich Ltd) and incubated (model Bacterial Incubator 250, LMS Ltd) for $16 \mathrm{~h}$ at $30{ }^{\circ} \mathrm{C}$. The number of colonies visible at each dilution were then counted by eye. All tests were performed in triplicate. The cells were unaffected by vortexing (or ultrasonication (model U50, manufacturer Ultrawave Ltd)) and fully removed from the sample surface, Fig. S1 and S2 $(\mathrm{ESI} \dagger)$. The $\log _{10}$ reduction value for a treated sample was calculated relative to a control untreated sample. For each experiment, treated and untreated substrates were exposed to bacteria in parallel and incubated under identical conditions for the same time period before recovery and viability measurement. This test method to quantify the number of bacteria killed following exposure to treated substrates was chosen because cinnamaldehyde is not readily soluble in aqueous media and therefore its efficacy will be localised at the functionalised substrate surface which promotes compatibility with cinnamaldehyde. The high numbers of bacteria recovered from untreated substrates provides good evidence that the method is effective. Furthermore, the vortex mixer agitates the samples at 2000$3000 \mathrm{rpm}$, and is fully capable of removing bacteria from surfaces.

For antibacterial recycling tests the same procedure as described above was followed, with the variation that, the substrates were taken out from the $10^{-1}$ dilution solution microtubes (prepared following $4 \mathrm{~h}$ bacteria incubation at
$30{ }^{\circ} \mathrm{C}$ ), rinsed with ultrapure water (approximately $50 \mathrm{ml}$ ) for $1 \mathrm{~min}$ at $20{ }^{\circ} \mathrm{C}$ and then completely air-dried overnight before the next use cycle. Consecutive repeat tests were performed using the same samples, with the mid-log bacterial culture being dispensed onto the same side of the substrate each time. All tests were performed in triplicate.

For scanning electron microscopy (SEM), PET film substrates which had been treated with bacteria were immersed overnight in glutaraldehyde ( $2 \%$ in Sorenson phosphate buffer, TAAB Laboratories Equipment Ltd), then removed and rinsed with Milli-Q ${ }^{\circledR}$ grade water to remove any excess glutaraldehyde. Next, the PET film substrates were mounted onto carbon disks supported on aluminium stubs and coated with a thin gold layer (5-10 nm, Polaron SEM Coating Unit, Quorum Technologies Ltd). Images were acquired using a scanning electron microscope (model Vega 3LMU, Tescan Orsay Holdings a.s.) operating in secondary electron detection mode, in conjunction with an $8 \mathrm{kV}$ accelerating voltage, and a working distance of 8-11 mm.

\section{Results}

\section{Polydopamine-cinnamaldehyde coating}

For the cinnamaldehyde-only control treatment, the cinnamaldehyde oil sunk to the bottom of the aqueous tris(hydroxymethyl) aminomethane solution in the vial. However, vigorous shaking of the vial for a few seconds turned the solution milky in appearance (due to the suspension of cinnamaldehyde in water). A slight colour change to yellow was seen in the solution. No solid formation was observed over a period of time, until eventually the cinnamaldehyde constituent slowly coalesced to separate out from the aqueous phase.

Immersion of PET film substrate into the polydopamine-only coating solution gave rise to the appearance of a dark grey-black polydopamine surface layer, Fig. 1. Over the course of the reaction, the polydopamine precursor solution simultaneously

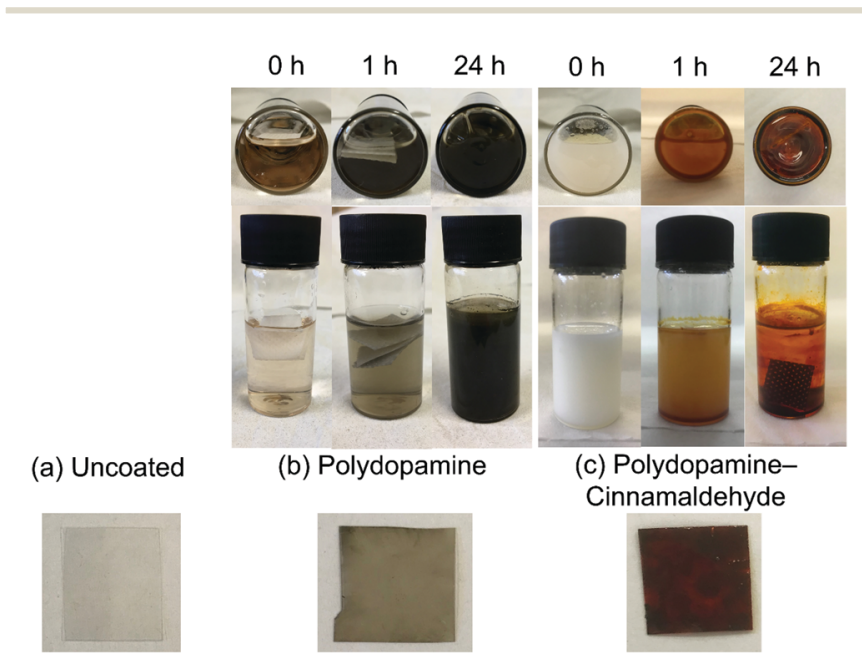

Fig. 1 Photographs of coating solutions and $15 \times 15 \mathrm{~mm}$ PET film substrate: (a) uncoated; (b) polydopamine-only; and (c) polydopaminecinnamaldehyde. 
turned from colourless to black within the vial due to polydopamine precipitate formation.

For the combined polydopamine-cinnamaldehyde system, addition of the aqueous tris(hydroxymethyl)aminomethane solution to the dopamine hydrochloride and cinnamaldehyde solid-liquid mixture led to the dopamine hydrochloride dissolving, and the cinnamaldehyde settling at the bottom of the vial. After vigorous shaking of the vial for a few seconds, the solution turned milky in appearance (due to the suspension of cinnamaldehyde oil in the aqueous medium-as described above), Fig. 1. Over time, the white cloudiness faded away. However, no black colouration indicative of polydopamine was observed at any point during the reaction-neither on the substrates, nor in the solution. Instead, the white cloudiness disappeared to give a clear solution with a slight yellow colour. This was accompanied by the formation of a red coating on the substrates (as well as on the vial bottoms), Fig. 1. The mass increase of PET film following polydopamine-cinnamaldehyde coating was measured to be $4.4 \pm 0.9 \mathrm{mg} \mathrm{cm}^{-2}$ (assuming both sides are coated), Table 1. A range of different substrates could be coated by this method, including PET, polypropylene, silicon wafer, and glass.

Cinnamaldehyde oil and the polydopamine-cinnamaldehyde coatings were characterised by infrared spectroscopy, Fig. 2. Liquid cinnamaldehyde absorption bands include aromatic and alkene $\mathrm{C}-\mathrm{H}$ stretching (around $3060 \mathrm{~cm}^{-1}$ ), aldehyde $\mathrm{C}-\mathrm{H}$ stretching $\left(2814 \mathrm{~cm}^{-1}\right.$ and $\left.2742 \mathrm{~cm}^{-1}\right), \mathrm{C}=\mathrm{O}$ stretching $\left(1668 \mathrm{~cm}^{-1}\right)$, as well as aromatic $\mathrm{C}=\mathrm{C}$ stretching $\left(1625 \mathrm{~cm}^{-1}\right) .{ }^{58}$ Polydopamine-only coated silicon wafer displayed broad absorbances around $3220 \mathrm{~cm}^{-1}$ corresponding to $\mathrm{O}-\mathrm{H}$ groups, and $1605 \mathrm{~cm}^{-1}$ and $1509 \mathrm{~cm}^{-1}$ from $\mathrm{C}=\mathrm{C}$ stretching. ${ }^{59}$ For the case of polydopamine-cinnamaldehyde coated silicon wafer, the characteristic cinnamaldehyde absorbances were still visible, as well as a broad polydopamine $\mathrm{O}-\mathrm{H}$ group absorption around $3220 \mathrm{~cm}^{-1}$, together with a small polydopamine aromatic $\mathrm{C}=\mathrm{C}$ stretching peak at $1509 \mathrm{~cm}^{-1}$ (both of these latter features are absent for pure cinnamaldehyde ${ }^{58}$ ).

Cinnamaldehyde displays an intense UV-Vis absorbance peak at $\lambda=290 \mathrm{~nm}$, but no other features, Fig. 3. ${ }^{61,62}$ Polydopamine coated quartz showed a weaker UV-Vis absorbance peak at $\lambda=290 \mathrm{~nm}$, as well as broad absorption across the $200-800 \mathrm{~nm}$ wavelength range, Fig. $3^{63}$ Polydopaminecinnamaldehyde coated quartz exhibited a strong absorbance

Table 1 Mass increase for polydopamine-cinnamaldehyde, polyethyleneimine-cinnamaldehyde, and tannic acid-cinnamaldehyde coated non-porous PET film substrates, and cinnamaldehyde treated nonwoven polypropylene cloth. $15 \mathrm{~mm} \times 15 \mathrm{~mm}$ sample size

\begin{tabular}{ll} 
Coating & $\begin{array}{l}\text { Mass increas } \\
\mathrm{mg} \mathrm{cm}^{-2}\end{array}$ \\
\hline Polydopamine-cinnamaldehyde/PET film & $4.4 \pm 0.9^{a}$ \\
Polyethyleneimine-cinnamaldehyde/PET film & $0.7 \pm 0.3^{a}$ \\
Tannic acid-cinnamaldehyde/PET film & $1.0 \pm 0.2^{a}$ \\
Cinnamaldehyde/non-woven polypropylene cloth & $45 \pm 4$
\end{tabular}

${ }^{a}$ Assuming both sides are coated.

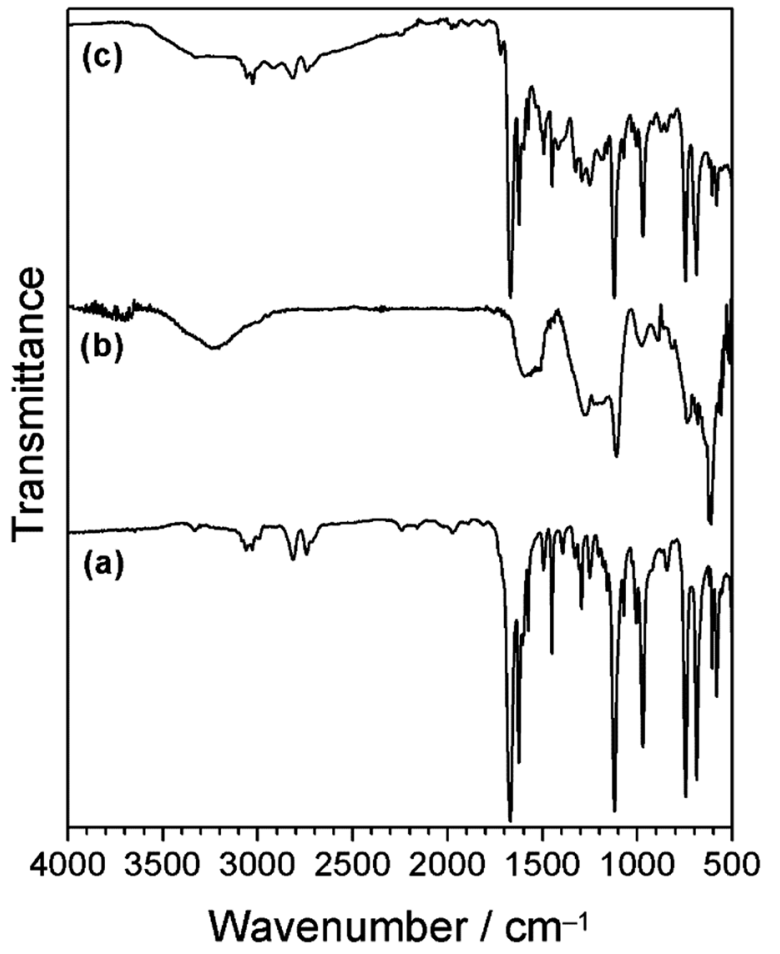

Fig. 2 Infrared spectra of: (a) cinnamaldehyde; (b) polydopamine-only coating; and (c) polydopamine-cinnamaldehyde coating. Schiff base imine absorbance should appear around $1640 \mathrm{~cm}^{-1}$-this absorbance is not distinguishable due to overlap with strong cinnamaldehyde peaks. ${ }^{60}$

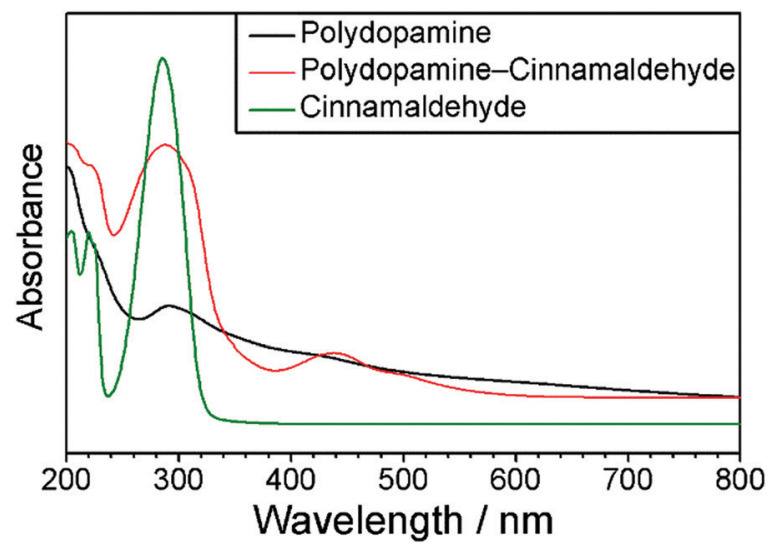

Fig. 3 UV-Vis spectra of cinnamaldehyde solution; polydopamine coated quartz; and polydopamine-cinnamaldehyde coated quartz.

at $\lambda=288 \mathrm{~nm}$, which can be attributed to either or both of the cinnamaldehyde and dopamine coating constituents. In addition, a new absorbance peak at $\lambda=438 \mathrm{~nm}$ is apparent (which was absent in both the aforementioned cinnamaldehyde and polydopamine UV-Vis spectra)-this accounts for the observed red coating colour and is indicative of chemical bond formation (reaction) between polydopamine and cinnamaldehyde causing a change in electron density within the host polydopamine structure (hence UV-Vis excitation). 
Previously it has been reported that polydopamine can undergo an aza-Michael reaction with acrylate groups, where the polydopamine amine group nitrogen lone pair attacks the carbon-carbon double bond of the acrylate group to form a new bond. ${ }^{13}$ Given that cinnamaldehyde contains an alkene bond adjacent to a carbonyl group, an analogous Michael or Aza-Michael type reaction may be anticipated. However, other studies have shown that an amine group nitrogen lone pair can react via nucleophilic attack at the cinnamaldehyde carbonyl group to form a Schiff base imine product. ${ }^{64,65}$ Therefore, in order to elucidate the reaction mechanism for exactly how cinnamaldehyde reacts with dopamine/polydopamine, a mass spectrometric investigation was undertaken: cinnamaldehyde was reacted with an equimolar amount of phenethylamine-a compound analogous to dopamine but lacking the catechol $\mathrm{OH}$ groups (thereby unable to undergo polymerisation as observed for dopamine), Scheme 2. The obtained product was a viscous orange oil. Mass spectrometry of the product gave mass 236.1 $m / z$ (which is consistent with the empirical formula $\mathrm{C}_{17} \mathrm{H}_{17} \mathrm{~N}$ and the Schiff base imine product molecular ion $\left.[\mathrm{M}+\mathrm{H}]^{+}\right)$, Fig S3 (ESI $\dagger$ ). No mass fragment was measured for the alternative Michael addition product ion expected at $253 \mathrm{~m} / \mathrm{z}$. Hence, cinnamaldehyde reacts with dopamine/polydopamine to form a Schiff base imine product. Tris(hydroxymethyl)aminomethane was not included in this reaction in order that only the reaction between phenethylamine and cinnamaldehyde could be investigated. Although tris(hydroxymethyl)aminomethane has been reported to react with polydopamine during coating deposition, this does not occur via the Schiff base reaction. ${ }^{66,67}$ There also is in addition the possibility of tris(hydroxymethyl)aminomethane undergoing the Schiff base reaction with cinnamaldehyde to form imine linkages.

Control cinnamaldehyde treated PET samples had a very small antibacterial effect against both Gram-negative $E$. coli and Gram-positive $S$. aureus (this could be due to a low amount of residual cinnamaldehyde remaining on the PET film surface after the final washing step), Table 2. Polydopamine-coated PET film showed no antibacterial activity against $E$. coli and a very minor effect for $S$. aureus (less than $\log _{10}$ Reduction $=1$ ). Whereas, polydopamine-cinnamaldehyde coated PET film displayed complete killing of both types of bacteria (exceeding $\log _{10}$ Reduction $\left.=7\right)$-which easily exceeds the minimal $\left(\log _{10}\right.$ Reduction > 3) set by the US Environmental Protection Agency Office (EPA) ${ }^{68}$ Following addition of $900 \mu \mathrm{l}$ of sterile LuriaBertani broth media into each microtube containing sample and vortexing, the polydopamine-cinnamaldehyde coated PET film was aseptically removed. To further assess the efficacy of bacterial killing, viability experiments were performed on the

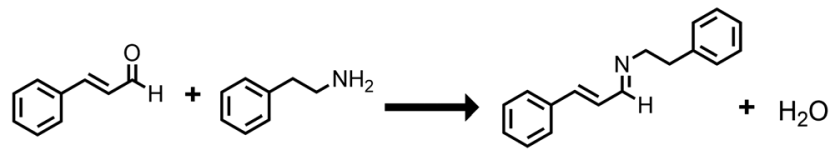

Scheme 2 Reaction of cinnamaldehyde with phenethylamine to form Schiff base imine product.
Table 2 Antibacterial activities for PET film coated with: polydopamine; polydopamine-cinnamaldehyde; polyethyleneimine-cinnamaldehyde; tannic acid; or tannic acid-cinnamaldehyde. $\log _{10}$ Reduction values are calculated relative to the untreated substrate (mean \pm standard deviation)

\begin{tabular}{|c|c|c|}
\hline \multirow[b]{2}{*}{ Dipping solution } & \multicolumn{2}{|c|}{$\underline{\text { Bacteria } \operatorname{loss} / \log _{10} \text { reduction }}$} \\
\hline & $\begin{array}{l}\text { E. coli } \\
\text { (Gram-negative) }\end{array}$ & $\begin{array}{l}\text { S. aureus } \\
\text { (Gram-positive) }\end{array}$ \\
\hline Cinnamaldehyde $^{a}$ & $0.12 \pm 0.07$ & $0.29 \pm 0.07$ \\
\hline Polydopamine $^{a}$ & 0.00 & $0.34 \pm 0.06$ \\
\hline Polydopamine-cinnamaldehyde & $8.15 \pm 0.03$ & $7.68 \pm 0.05$ \\
\hline Polyethyleneimine $^{a}$ & 0.00 & 0.00 \\
\hline Polyethyleneimine-cinnamaldehyde & $3.87 \pm 0.56$ & $7.44 \pm 0.03$ \\
\hline Tannic acid $^{a}$ & 0.00 & $0.13 \pm 0.07$ \\
\hline Tannic acid-cinnamaldehyde & $8.33 \pm 0.03$ & $7.56 \pm 0.06$ \\
\hline \multicolumn{3}{|c|}{$\begin{array}{l}{ }^{a} \text { Control samples comprised immersion of PET film in } 15 \mathrm{mg} \mathrm{ml}^{-1} \\
\text { cinnamaldehyde aqueous solution, or } 20 \mathrm{mg} \mathrm{ml}^{-1} \text { polyethyleneimine } \\
\text { aqueous solution, or } 3 \mathrm{mg} \mathrm{ml}^{-1} \text { tannic acid aqueous solution followed } \\
\text { by rinsing in water. }\end{array}$} \\
\hline
\end{tabular}

retained cultures in the $1 \mathrm{ml}$ solution. Firstly, $100 \mu \mathrm{l}$ of the solution was spread onto Luria-Bertani agar plates. After incubation at $37{ }^{\circ} \mathrm{C}$, no colonies were observed, Fig. S4 (ESI $\dagger$ ). Then the remaining $900 \mu \mathrm{l}$ of bacteria solution was centrifuged to pellet any bacteria present and resuspended in $100 \mu \mathrm{l}$ of phosphate-buffered saline followed by spreading onto fresh Luria-Bertani agar plates-again, no growth was observed, Fig. S5 (ESI $\dagger)$. Whereas, the viability of E. coli on untreated PET film control samples gave an average of $3.6 \times 10^{9} \mathrm{CFU} \mathrm{ml}^{-1}$ (or $3.6 \times 10^{8} \mathrm{CFU}$ per $100 \mu \mathrm{l}$ of bacteria solution), Fig. S1 (ESI $\dagger$ ). When $100 \mu \mathrm{l}$ from the $1 \mathrm{ml}$ bacteria solution from untreated PET film control samples was spread onto Luria-Bertani agar plates, after incubation, confluent bacteria growth was observed, Fig. S4 (ESI $\dagger$ ). These results confirm that exposure of $E$. coli to the polydopamine-cinnamaldehyde coated PET film does indeed kill all the bacteria present in the exposed bacteria-containing solution. The measured antibacterial activity was retained during recycling tests against $E$. coli for the first two tests, followed by a gradual loss of efficacy during further recycling, Fig. 4.

In order to further examine the mechanism of antibacterial activity, time-resolved UV-Vis spectroscopy studies were performed using the polydopamine-cinnamaldehyde coated PET film, Fig. 5. Release of cinnamaldehyde into water from the host coating showed a rapid increase followed by levelling off after $24 \mathrm{~h}$. This is consistent with the antibacterial recycle testing, which showed a gradual drop-off in efficacy, Fig. 4.

\section{Polyethyleneimine-cinnamaldehyde coating}

Polyethyleneimine was utilised to develop further understanding, given that it contains amine groups like polydopamine, and therefore polyethyleneimine should undergo the Schiff base reaction with cinnamaldehyde to form an antibacterial coating, Scheme 1. Solution mixtures utilising varying ratios of polyethyleneimine to cinnamaldehyde were screened in order to determine optimal quantities of both components for the production of a high efficacy antibacterial coating. Mixing of polyethyleneimine solution with cinnamaldehyde led to the 


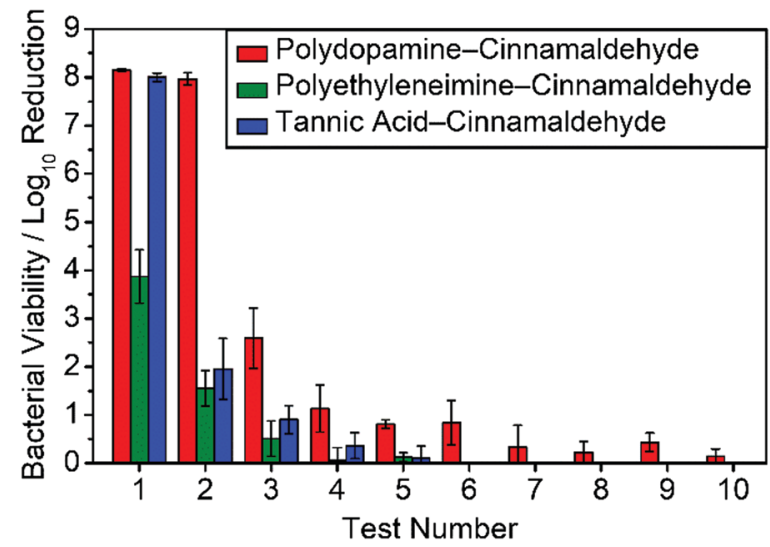

Fig. 4 Recycle antibacterial activity against $E$. coli for coated PET films: polydopamine-cinnamaldehyde; polyethyleneimine-cinnamaldehyde: and tannic acid-cinnamaldehyde. $\log _{10}$ Reduction values are calculated relative to the untreated PET substrate (mean \pm standard deviation) Following each antibacterial test, samples were rinsed with water for 1 min at $20{ }^{\circ} \mathrm{C}$ and completely air-dried prior to the next re-use.

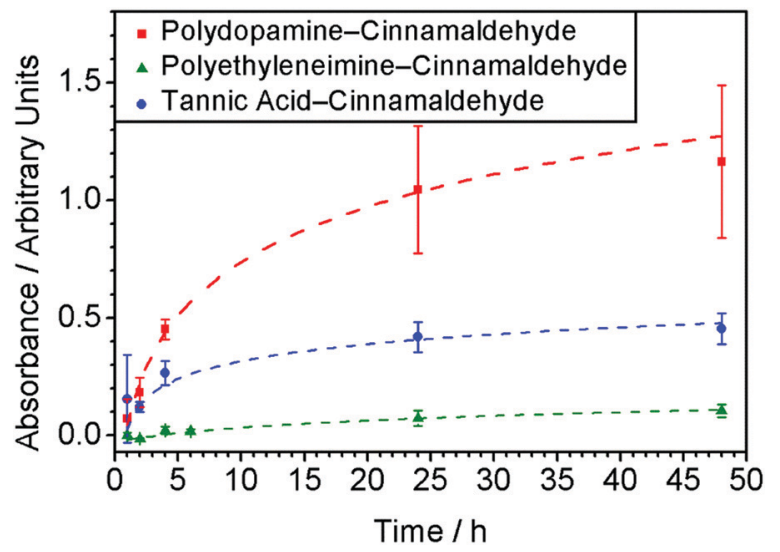

Fig. 5 Release of cinnamaldehyde from antibacterial coatings into water at $20^{\circ} \mathrm{C}$ monitored by UV-Vis spectroscopy $(\lambda=290 \mathrm{~nm})$ : polydopaminecinnamaldehyde; polyethyleneimine-cinnamaldehyde; and tannic acidcinnamaldehyde.

formation of an off-white precipitate which was found to uniformly adhere onto the test substrates (as well as onto the bottom of the glass vials), and remained unchanged in appearance following washing with water. For formulations where a higher weight proportion of polyethyleneimine relative to cinnamaldehyde was used, much less precipitate was found to form. Whereas excess cinnamaldehyde compared to polyethyleneimine led to a yellow solution, and practically no adhesive precipitate formed on the substrate. Equal masses of polyethyleneimine and cinnamaldehyde yielded good performance coatings $\left(20 \mathrm{mg} \mathrm{ml}^{-1}\right.$ polyethyleneimine and $20 \mathrm{mg} \mathrm{ml}^{-1}$ cinnamaldehyde mixture solutions were chosen for further studies). The mass increase following coating of PET substrates was measured to equal $0.71 \mathrm{mg} \mathrm{cm}^{-2}$ (assuming both sides are coated), Table 1 .

Infrared absorption peaks for polyethyleneimine include $\mathrm{N}-\mathrm{H}$ stretching $\left(3275 \mathrm{~cm}^{-1}\right)$, aliphatic $\mathrm{C}-\mathrm{H}$ stretching
(2930-2810 $\mathrm{cm}^{-1}$ ), primary amine group $\mathrm{NH}_{2}$ bending $\left(1580 \mathrm{~cm}^{-1}\right)$, and $\mathrm{CH}_{2}$ symmetric bending vibration $\left(1460 \mathrm{~cm}^{-1}\right)$, Fig. $6 .^{69,70}$ The polyethyleneimine-cinnamaldehyde coating showed a broad absorption peak around $3300 \mathrm{~cm}^{-1}$, corresponding to $\mathrm{N}-\mathrm{H}$ stretching. A new feature at $1634 \mathrm{~cm}^{-1}$ is present, consistent with imine bond formation following the Schiff base reaction between amine groups from polyethyleneimine and cinnamaldehyde (akin to the reactions between phenethylamine/ polydopamine and cinnamaldehyde), Scheme 2. Otherwise, many of the infrared fingerprint region absorption bands of cinnamaldehyde and polyethyleneimine overlap with the polyethyleneiminecinnamaldehyde spectrum.

PET films immersed in polyethyleneimine-only $20 \mathrm{mg} \mathrm{ml}^{-1}$ aqueous solution followed by washing in ultrapure water and drying for at least $3 \mathrm{~h}$ at $20{ }^{\circ} \mathrm{C}$ were tested as a control and found to possess no antibacterial activity, Table 2 . Whereas, the polyethyleneimine-cinnamaldehyde coated PET films showed at least $\log _{10}$ Reduction $=3$ or 4 against $E$. coli, and complete killing (exceeding $\log _{10}$ Reduction $=7$ ) for $S$. aureus. Antibacterial recycling tests were carried out against $E$. coli, and there was a drop in bacterial killing following the second test with practically all biocidal activity lost after the fourth test, Fig. 4 .

The release behaviour of the polyethyleneimine-cinnamaldehyde coating in water was further investigated by immersion of coated PET substrates into water for $24 \mathrm{~h}$ at $20{ }^{\circ} \mathrm{C}$ whilst shaking. $0.5 \pm 0.4 \mathrm{mg} \mathrm{cm} \mathrm{cm}^{-2}$ of material was released after $24 \mathrm{~h}$, and $0.22 \pm 0.14 \mathrm{mg} \mathrm{cm}^{-2}$ of the coating remained.

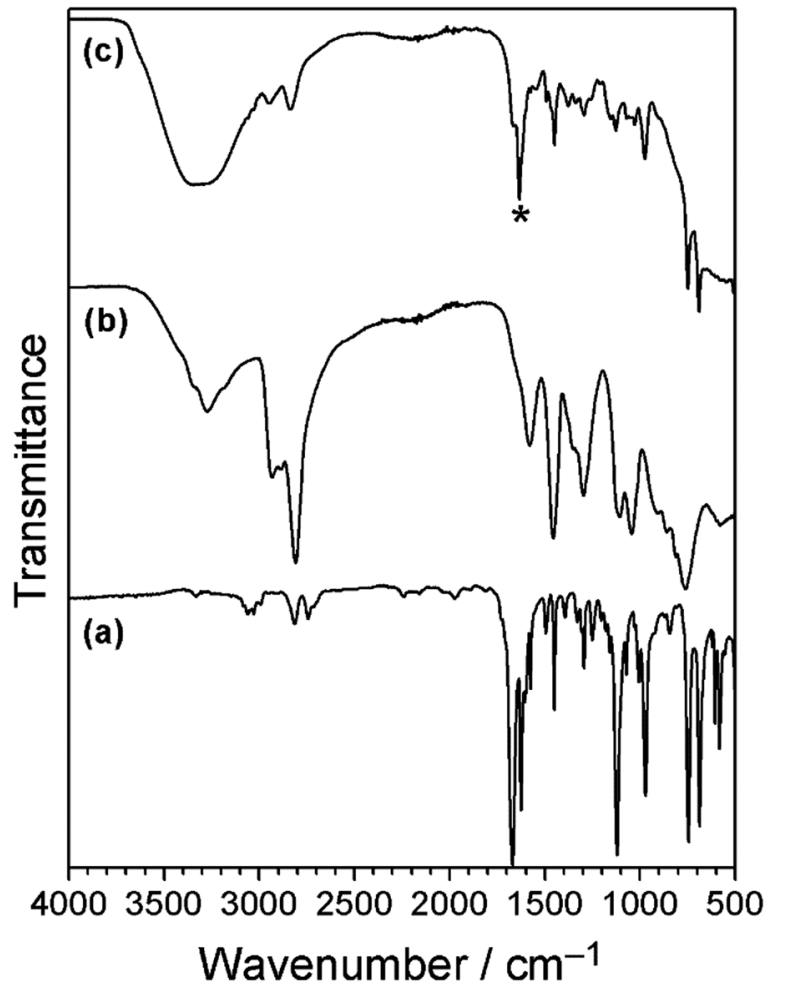

Fig. 6 Infrared spectra of: (a) cinnamaldehyde; (b) polyethyleneimine; and (c) polyethyleneimine-cinnamaldehyde coating. ${ }^{*}$ New imine feature at $1634 \mathrm{~cm}^{-1}$. 
Visually, there did not seem to be any alteration to the appearance of the coatings. This would suggest that the observed mass loss following immersion in water for $24 \mathrm{~h}$ is due to the release of trapped or loosely bound cinnamaldehyde and/or polyethyleneimine.

Time-resolved UV-Vis spectroscopy studies were performed using the polyethyleneimine-cinnamaldehyde coated PET films in order to determine the release profile of cinnamaldehyde into aqueous solution from the coating, Fig. 5. A much lower cinnamaldehyde absorbance was measured compared to the polydopamine-cinnamaldehyde system, which is consistent with the polyethyleneimine-cinnamaldehyde coating being a lot thinner and thereby losing its recycling antibacterial activity faster compared to the polydopamine-cinnamaldehyde coating, Table 1 and Fig. 4.

\section{Tannic acid-cinnamaldehyde coating}

Tannic acid-only coatings were found to be very thin; whilst tannic acid-cinnamaldehyde coatings appeared to be much thicker. Variation in tannic acid-cinnamaldehyde solution composition was explored in order to provide the optimum coating: $3.0,4.5,6.0$, and $15 \mathrm{mg} \mathrm{ml}^{-1}$ cinnamaldehyde combined with fixed $3 \mathrm{mg} \mathrm{ml}^{-1}$ tannic acid (corresponding to a tannic acid: cinnamaldehyde mass ratio of $1: 1,1: 1.5,1: 2$, and $1: 5$ respectively). The solid coating obtained using a 1:1 mass ratio was yellow in appearance and evenly covered the PET film, whereas all of the other solution compositions yielded oily (non-solid), non-uniform coatings on the PET film surfaces, Fig. 7. Hence, $3 \mathrm{mg} \mathrm{ml}^{-1}$ cinnamaldehyde- $3 \mathrm{mg} \mathrm{ml}^{-1}$ tannic acid mixture coating solution was chosen for further investigation. The mass increase for this tannic acid-cinnamaldehyde coating was $1.0 \pm 0.2 \mathrm{mg} \mathrm{cm}^{-2}$ (assuming both sides of each substrate are coated), Table 2 .

The infrared spectrum of tannic acid displays absorbances for $\mathrm{O}-\mathrm{H}$ groups $\left(3300 \mathrm{~cm}^{-1}\right), \mathrm{C}=\mathrm{O}$ stretching $\left(1700 \mathrm{~cm}^{-1}\right)$, and three peaks at $1605 \mathrm{~cm}^{-1}, 1530 \mathrm{~cm}^{-1}$ and $1444 \mathrm{~cm}^{-1}$ associated with aromatic ring stretching, Fig. $8 .^{21}$ For the tannic acidcinnamaldehyde coating, the infrared spectrum resembles the tannic acid spectrum. In addition, there is a new absorbance at $1649 \mathrm{~cm}^{-1}$, characteristic of imine group $\mathrm{C}=\mathrm{N}$ stretching (which appears at a lower wavenumber compared to the cinnamaldehyde $\mathrm{C}=\mathrm{O}$ stretching vibration $\left.\left(1670 \mathrm{~cm}^{-1}\right)\right)$. An explanation for this new imine peak could be the Schiff base reaction product between tris(hydroxymethyl)aminomethane and cinnamaldehyde (this may also explain the formation of yellow colour in the

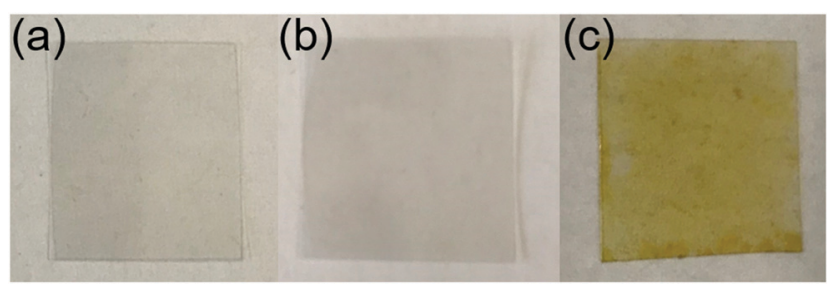

Fig. 7 Photographs of PET film: (a) uncoated; (b) tannic acid-only coating; and (c) tannic acid-cinnamaldehyde coating.

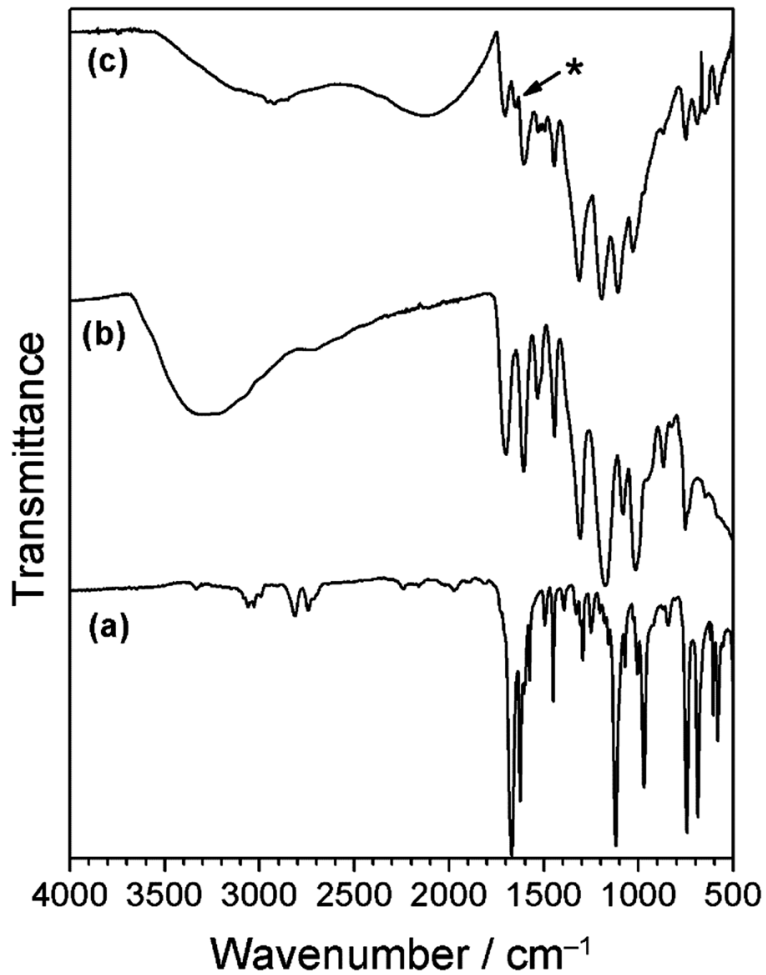

Fig. 8 Infrared spectra of: (a) cinnamaldehyde; (b) tannic acid; and (c) tannic acid-cinnamaldehyde coating. * New imine feature at $1649 \mathrm{~cm}^{-1}$.

cinnamaldehyde control solution mentioned previously-the cinnamaldehyde and tris(hydroxymethyl)aminomethane react to form a yellow Schiff base imine product). Previously it has been reported that tris(hydroxymethyl)aminomethane can undergo Schiff base reaction with carbonyl-containing compounds, yielding $\mathrm{C}=\mathrm{N}$ infrared stretching frequencies in the region of 1640$1630 \mathrm{~cm}^{-1} \cdot{ }^{71,72}$ Tris(hydroxymethyl)aminomethane and cinnamaldehyde are present in almost equimolar amounts in the tannic acid-cinnamaldehyde coating solution, whereas in the polydopamine-cinnamaldehyde coating solution there is a significant excess of cinnamaldehyde relative to tris(hydroxymethyl) aminomethane (which masks the imine bond region of the infrared absorption). Tannic acid is also capable of reacting with amines via the Schiff base reaction to form an iminehowever, the wavenumber for such imine group stretching should be much lower $\left(1585 \mathrm{~cm}^{-1}\right)$, thus making it unlikely that this new peak is due to the reaction of tannic acid with tris(hydroxymethyl)aminomethane to form an imine. ${ }^{73}$

Tannic acid-only coated PET film displayed no antibacterial activity against $E$. coli and only a modest reduction in viability against $S$. aureus, Table 2 . The tannic acid-cinnamaldehyde coating was found to give rise to complete killing of both types of bacteria (exceeding $\log _{10}$ reduction $=7$ ). Antibacterial recycling tests performed with $E$. coli for the tannic acidcinnamaldehyde coated PET film showed a decrease in antibacterial activity after the first test, and negligible activity was found by the fifth test, Fig. 4. A possible reason for why the tannic acid-cinnamaldehyde coating does not display as 
long-lasting antibacterial activity as the polydopaminecinnamaldehyde coating could be as a consequence of the smaller amount of cinnamaldehyde used to prepare the coatings ( $3 \mathrm{mg} \mathrm{ml}^{-1}$ versus $15 \mathrm{mg} \mathrm{ml}^{-1}$ solutions respectively), or due to the coating being thinner, Table 1.

Time-resolved UV-Vis spectroscopy studies were performed using tannic acid-cinnamaldehyde coated PET film in order to follow the release of cinnamaldehyde from the coating into the aqueous phase, Fig. 5 . The amount of cinnamaldehyde release measured for the tannic acid-cinnamaldehyde coatings was lower compared to the polydopamine-cinnamaldehyde coatings, and can be attributed to the smaller concentration of cinnamaldehyde employed to prepare the former $\left(3 \mathrm{mg} \mathrm{ml}^{-1}\right.$ versus $15 \mathrm{mg} \mathrm{ml}{ }^{-1}$ solutions respectively), or because the coating is thinner, Table 1 . This correlates with the antibacterial recycling tests, where the tannic acid-cinnamaldehyde coated PET film showed a faster decline in antibacterial activity relative to the polydopamine-cinnamaldehyde coated PET film, Fig. 4.

\section{Cinnamaldehyde-porous substrates}

Given that cinnamaldehyde loading in the coating has been shown to be a key factor governing antibacterial recycling capacity (Fig. 4 and 5), non-woven polypropylene host substrate containing a larger open pore structure (micron scale) was impregnated with cinnamaldehyde, Table $1 .^{74}$ The cloth pieces were weighed before and after impregnation of cinnamaldehyde, and the average mass increase was measured to be $45 \pm 4 \mathrm{mg} \mathrm{cm}^{-2}$, Table 1.

Testing against $E$. coli and $S$. aureus showed complete killing of the bacteria $\left(\log _{10}\right.$ reduction $=8.31 \pm 0.12$ and $7.76 \pm 0.07$ respectively). Seventeen consecutive antibacterial recycling tests against E. coli. (equivalent to continuous contact with bacteria in liquid for $68 \mathrm{~h}$ ), showed that the cloths killed all bacteria in every test $\left(\log _{10}\right.$ reduction $\left.=\sim 8\right)$, Fig. 9. The observed high antibacterial activity over such a prolonged period of recycling rules out the possibility of live bacteria cells just sticking to the cloth surface-which is consistent with the previously reported biocidal activity of cinnamaldehyde. ${ }^{41-43}$

Since cinnamaldehyde was found to impregnate into porous non-woven polypropylene cloth without the need for any extra reagents (e.g. aforementioned polydopamine, polyethyleneimine, tannic acid or tris(hydroxymethyl)aminomethane), alternative porous material substrates were also evaluated in order to assess the broader applicability of this approach. Porous polytetrafluoroethylene (PTFE) membrane was chosen as a more hydrophobic type of material. Untreated PTFE membrane exhibited no antibacterial activity, whereas the cinnamaldehyde impregnated PTFE membrane gave rise to complete killing of E. coli $\left(\log _{10}\right.$ reduction $\left.=8.27 \pm 0.04\right)$.

Considering that the aforementioned polypropylene and PTFE porous substrates are both hydrophobic and therefore unlikely to absorb water in preference to cinnamaldehyde whilst immersed in aqueous solution, cotton fabric was selected as a hydrophilic porous material for comparison. Untreated cotton displayed no antibacterial effect, whereas the cinnamaldehyde impregnated cotton pieces killed all

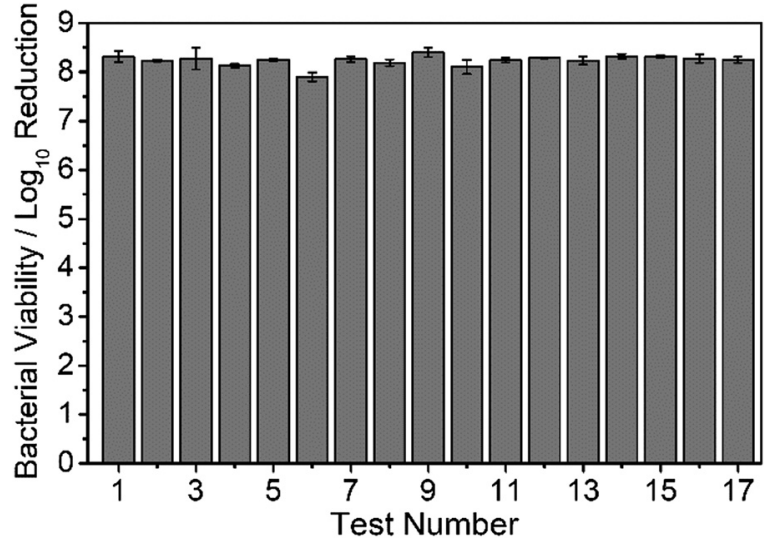

Fig. 9 E. coli antibacterial recycling of cinnamaldehyde impregnated non-woven polypropylene cloth. Values are reported as the average $\log _{10}$ reduction relative to untreated non-woven polypropylene cloth (average \pm standard deviation).

E. coli $\left(\log _{10}\right.$ reduction $\left.=8.29 \pm 0.06\right)$, thereby confirming that the hydrophilic cotton was capable of sufficient cinnamaldehyde uptake to subsequently provide a strong antibacterial efficacy.

\section{Discussion}

Polydopamine, tannic acid, and cinnamaldehyde are all biodegradable and not harmful to human health. ${ }^{1,75-78}$ The polydopamine-cinnamaldehyde, polyethyleneimine-cinnamaldehyde, and tannic acid-cinnamaldehyde coatings exhibit strong antibacterial activity against both Gram-negative and Gram-positive bacteria. They retained their red, off-white, and yellow colours respectively following antibacterial test recycling. This indicates that the coatings are well adhered to the underlying substrates, and the solid host polymer coating alone cannot be responsible for the observed antibacterial activity. Cinnamaldehyde interacts with the polydopamine, polyethyleneimine, or tannic acid during coating formation, either reacting, binding via non-covalent interactions, or becoming trapped within the polymer coating. Cinnamaldehyde reaction within the host polymers provides compatibilization for excess cinnamaldehyde oil-the surface energies of the solid and fluid become better matched, leading to highly stable entrapped cinnamaldehyde liquid. Cinnamaldehyde is then able to leach out (release) during the antibacterial testing studies (Fig. 4 and 5). Once the cinnamaldehyde becomes depleted, there is no longer any antibacterial activity. Amongst these coatings, the polydopaminecinnamaldehyde system displays the best recycling properties, and this correlates to its extended release of cinnamaldehyde over a longer period of time, Fig. 4 and 5 . Whereas, the solution for polyethyleneimine-cinnamaldehyde coated PET film after $48 \mathrm{~h}$ immersion in water displayed a lower final UV-Vis absorbance compared to polydopamine-cinnamaldehyde or tannic acid-cinnamaldehyde coated PET films, Fig. 5. This correlates with its lower overall antibacterial efficacy against E. coli, as well as quicker loss of activity during antibacterial 
recycling, and with its smaller mass increase (thickness), Tables 1, 2 and Fig. 4.

Unlike dopamine/polydopamine and polyethyleneimine, tannic acid does not contain amine functional groups, meaning that it cannot undergo the Schiff base reaction with cinnamaldehyde as occurs for dopamine/polydopamine and polyethyleneimine. Rather tris(hydroxymethyl)aminomethane plays a dual role both initiating oxidative polymerisation of tannic acid and reacting with cinnamaldehyde via Schiff base mechanism which in turn may help to entrap cinnamaldehyde through compatibilization. The trapped tris(hydroxymethyl)aminomethanecinnamaldehyde Schiff base product may also be antibacterial. Another possibility is that tannic acid and cinnamaldehyde interact with each other via non-covalent bonding such as $\pi-\pi$ interactions, hydrogen bonding or hydrophobic interactions to form an insoluble coating, with excess less strongly bound cinnamaldehyde able to release into water. Alternative conceivable mechanisms could include an oxa-Michael type reaction (whereby tannic acid $\mathrm{OH}$ groups are deprotonated by base to form an oxyanion which then performs a nucleophilic attack on the cinnamaldehyde alkene group leading to bond formation between the tannic acid and cinnamaldehyde).

Antibacterial activities have been reported previously for cinnamaldehyde impregnated into porous substrates including microporous polyurethane, ${ }^{58}$ polypropylene foot sweat pads, ${ }^{79}$ and wet wipes made from cellulose and polyester. ${ }^{80}$ However, no recycle/reuse testing was performed. Impregnation of cinnamaldehyde into porous hydrophobic (non-woven polypropylene cloth and polytetrafluoroethylene membrane) as well as into hydrophilic cotton through cinnamaldehyde entrapment is an effective means for incorporating large amounts of the essential oil into a substrate for multiple use antibacterial applications, Fig. 9. The inherent larger pore volumes (micron scale) and thicker materials provide greater cinnamaldehyde loading capacity leading to longer lasting antibacterial efficacies compared to the much thinner polydopamine-cinnamaldehyde, polyethyleneimine-cinnamaldehyde, and tannic acid-cinnamaldehyde coatings which contain essential oil dispersed on the nanoscale. The fact that the cinnamaldehyde impregnated non-woven polypropylene cloth shows no drop-off in antibacterial activity after 17 cycles of washing (equivalent to continuous contact with bacteria in liquid for $68 \mathrm{~h}$ ) indicates robustness, and this is entirely suitable for potential applications where reusability is desirable, Fig. 9. Alternative long-lasting antibacterial coatings include the use of silver nanoparticles and quaternary ammonium polymers. ${ }^{81,82}$ Both antimicrobial agents involve multiple synthesis steps and are damaging towards the environment. ${ }^{83,84}$ Whereas the present eco-friendly approach is a simple one-step process and can use natural biodegradable compounds such as dopamine, tannic acid, and cinnamaldehyde.

The present study opens up scope for the large scale, low cost fabrication of antibacterial coatings using plant-derived essential oil compounds (as alternatives to environmentally harmful metal-based systems). Naturally occurring and synthetic antimicrobial compounds could also be incorporated (including those with antiviral, antifouling, antifungal, or antiparasitic properties). These coating methods could also be extended to other natural and synthetic phenolic and polyphenol compound coatings besides polydopamine and tannic acid-such as derivatives of dihydroxyphenol (catechol) and pyrogallol (including gallic acid, epigallocatechin gallate, and epicatechin gallate). Potential applications include healthcare, prevention of the spread of pathogens and diseases, building materials, transportation, clothing, footwear, marine coatings, and active food packaging.

\section{Conclusions}

Coatings comprising cinnamaldehyde hosted within a compatible matrix on the nanoscale can be applied to a variety of substrates without the requirement for organic solvents or any further surface derivatization. Polydopamine-cinnamaldehyde coatings display high antibacterial efficacy towards both Gram-positive (S. aureus) and Gram-negative (E. coli) bacteria. Polyethyleneimine-cinnamaldehyde and tannic acid-cinnamaldehyde coatings also show good antibacterial activity against both $E$. coli and $S$. aureus. Cinnamaldehyde impregnated into a variety of porous substrates (non-woven polypropylene cloth, polytetrafluoroethylene membrane, and knitted cotton), exhibits strong antibacterial performance; with non-woven polypropylene cloth containing cinnamaldehyde providing long-lasting and recyclable antibacterial activity.

\section{Funding}

This work was supported by the British Council (Katip Çelebi Newton Fund grant reference 333595).

\section{Author contributions}

J. P. S. B and H. J. C. devised the concept, with assistance from G. J. S. and J. R. P. for antibacterial testing. Coatings were prepared by H. J. C and J. L. Infrared spectroscopy was conducted by H. J. C. UV-Vis analysis was undertaken by H. J. C. and J. L. Antibacterial testing was performed by H. J. C., P. S., J. R. P., and G. J. S. The manuscript was jointly drafted by J. P. S. B. and H. J. C. All authors gave final approval for publication.

\section{Conflicts of interest}

Durham University has filed an international patent application.

\section{Acknowledgements}

The following are thanked for technical assistance: D. Parker of the Department of Chemistry at Durham University for mass spectrometry; and T. Davey of the Electron Microscopy Unit at Newcastle University for SEM analysis. Data created during this research can be accessed at https://collections.durham.ac.uk. 


\section{References}

1 H. Lee, S. M. Dellatore, W. M. Miller and P. B. Messersmith, Mussel-Inspired Surface Chemistry for Multifunctional Coatings, Science, 2007, 318, 426-430.

2 J. H. Waite and M. L. Tanzer, Polyphenolic Substance of Mytilus edulis: Novel Adhesive Containing L-Dopa and Hydroxyproline, Science, 1981, 212, 1038-1040.

3 H. Lee, N. F. Scherer and P. B. Messersmith, SingleMolecule Mechanics of Mussel Adhesion, Proc. Natl. Acad. Sci. U. S. A., 2006, 103, 12999-13003.

4 Online Edition: "Combined Compendium of Food Additive Specifications" http:/www.fao.org/food/food-safety-quality/ scientific-advice/jecfa/jecfa-additives/detail/en/c/249/; accessed 10/05/2020.

5 T. S. Sileika, D. G. Barrett, R. Zhang, K. H. A. Lau and P. B. Messersmith, Colorless Multifunctional Coatings Inspired by Polyphenols Found in Tea, Chocolate, and Wine, Angew. Chem., Int. Ed., 2013, 52, 10766-10770.

6 Z. Lu, J. Xiao, Y. Wang and M. Meng, In Situ Synthesis of Silver Nanoparticles Uniformly Distributed on PolydopamineCoated Silk Fibers for Antibacterial Application, J. Colloid Interface Sci., 2015, 452, 8-14.

7 M. Sureshkumar, D. Y. Siswanto and C. K. Lee, Magnetic Antimicrobial Nanocomposite Based on Bacterial Cellulose and Silver Nanoparticles, J. Mater. Chem., 2010, 20, 6948-6955.

8 T. S. Sileika, H. D. Kim, P. Maniak and P. B. Messersmith, Antibacterial Performance of Polydopamine-Modified Polymer Surfaces Containing Passive and Active Components, ACS Appl. Mater. Interfaces, 2011, 3, 4602-4610.

9 T. He, W. Zhu, X. Wang, P. Yu, S. Wang, G. Tan and C. Ning, Polydopamine Assisted Immobilisation of Copper(II) on Titanium for Antibacterial Applications, Mater. Technol., 2015, 30, B68-B72.

10 J. Zhu, A. Uliana, J. Wang, S. Yuan, J. Li, M. Tian, K. Simoens, A. Volodin, J. Lin, K. Bernaerts, Y. Zhang and B. Van Der Bruggen, Elevated Salt Transport of Antimicrobial Loose Nanofiltration Membranes Enabled by Copper Nanoparticles Via Fast Bioinspired Deposition, J. Mater. Chem. A, 2016, 4, 13211-13222.

11 T. Shalev, A. Gopin, M. Bauer, R. W. Stark and S. Rahimipour, Non-Leaching Antimicrobial Surfaces through Polydopamine Bio-Inspired Coating of Quaternary Ammonium Salts or an Ultrashort Antimicrobial Lipopeptide, J. Mater. Chem., 2012, 22, 2026-2032.

12 H. Shi, L. Xue, A. Gao, Y. Fu, Q. Zhou and L. Zhu, FoulingResistant and Adhesion-Resistant Surface Modification of Dual Layer PVDF Hollow Fiber Membrane by Dopamine and Quaternary Polyethyleneimine, J. Memb. Sci., 2016, 498, 39-47.

13 C. Y. Liu and C. J. Huang, Functionalization of Polydopamine via the Aza-Michael Reaction for Antimicrobial Interfaces, Langmuir, 2016, 32, 5019-5028.

14 N. Mohd Daud, I. F. Saeful Bahri, N. A. N. Nik Malek, H. Hermawan and S. Saidin, Immobilization of Antibacterial
Chlorhexidine on Stainless Steel Using Crosslinking Polydopamine Film: Towards Infection Resistant Medical Devices, Colloids Surf., B, 2016, 145, 130-139.

15 S. He, P. Zhou, L. Wang, X. Xiong, Y. Zhang, Y. Deng and S. Wei, Antibiotic-Decorated Titanium with Enhanced Antibacterial Activity through Adhesive Polydopamine for Dental/Bone Implant, J. R. Soc., Interface, 2014, 11, 20140169.

16 K. Lim, R. R. Y. Chua, B. Ho, P. A. Tambyah, K. Hadinoto and S. S. J. Leong, Development of a Catheter Functionalized by a Polydopamine Peptide Coating with Antimicrobial and Antibiofilm Properties, Acta Biomater., 2015, 15, 127-138.

17 H. Lee, J. Rho and P. B. Messersmith, Facile Conjugation of Biomolecules onto Surfaces via Mussel Adhesive Protein Inspired Coatings, Adv. Mater., 2009, 21, 431-434.

18 Y. Yin, Y. Li, W. Cai and J. Sui, One-Step Deposition of Antibacterial Ag@Pdop Hybrid Films on an NiTi Alloy, $R S C$ Adv., 2019, 9, 29263-29272.

19 Z. Liu, Y. Hu, C. Liu and Z. Zhou, Surface-Independent OnePot Chelation of Copper Ions onto Filtration Membranes to Provide Antibacterial Properties, Chem. Commun., 2016, 52, 12245-12248.

20 J. Guo, W. Sun, J. P. Kim, X. Lu, Q. Li, M. Lin, O. Mrowczynski, E. B. Rizk, J. Cheng, G. Qian and J. Yang, Development of Tannin-Inspired Antimicrobial Bioadhesives, Acta Biomater., 2018, 72, 35-44.

21 S. Sagbas, N. Aktas and N. Sahiner, Modified Biofunctional p(Tannic Acid) Microgels and Their Antimicrobial Activity, Appl. Surf. Sci., 2015, 354, 306-313.

22 X. Li, P. Gao, J. Tan, K. Xiong, M. F. Maitz, C. Pan, H. Wu, Y. Chen, Z. Yang and N. Huang, Assembly of MetalPhenolic/Catecholamine Networks for Synergistically AntiInflammatory, Antimicrobial, and Anticoagulant Coatings, ACS Appl. Mater. Interfaces, 2018, 10, 40844-40853.

23 S. Yu, Y. Yin and J. Liu, Silver Nanoparticles in the Environment, Environ. Sci.: Processes Impacts, 2013, 15, 78-92.

24 A. Yan and Z. Chen, Impacts of Silver Nanoparticles on Plants: A Focus on the Phytotoxicity and Underlying Mechanism, Int. J. Mol. Sci., 2019, 20, 1003.

25 A. Panáček, L. Kvítek, M. Smékalová, R. Večeřová, M. Kolář, M. Röderová, F. Dyčka, M. Šebela, R. Prucek, O. Tomanec and R. Zbořil, Bacterial Resistance to Silver Nanoparticles and How to Overcome It, Nat. Nanotechnol., 2018, 13, 65-71.

26 A. Von Harpe, H. Petersen, Y. Li and T. Kissel, Characterization of Commercially Available and Synthesized Polyethylenimines for Gene Delivery, J. Controlled Release, 2000, 69, 309-322.

27 J. Lin, S. Qiu, K. Lewis and A. M. Klibanov, Bactericidal Properties of Flat Surfaces and Nanoparticles Derivatized with Alkylated Polyethylenimines, Biotechnol. Prog., 2002, 18, 1082-1086.

28 H. J. D. Dorman and S. G. Deans, Antimicrobial Agents from Plants: Antibacterial Activity of Plant Volatile Oils, J. Appl. Microbiol., 2000, 88, 308-316.

29 R. O. B. Wijesekera, A. L. Jayewardene and L. S. Rajapakse, Volatile Constituents of Leaf, Stem and Root Oils of 
Cinnamon (Cinnamomum zeylanicum), J. Sci. Food Agric., 1974, 25, 1211-1220.

30 G. Singh, S. Maurya, M. P. deLampasona and C. A. N. Catalan, A Comparison of Chemical, Antioxidant and Antimicrobial Studies of Cinnamon Leaf and Bark Volatile Oils, Oleoresins and Their Constituents, Food Chem. Toxicol., 2007, 45, 1650-1661.

31 S. G. Deans and G. Ritchie, Antibacterial Properties of Plant Essential Oils, Int. J. Food Microbiol., 1987, 5, 165-180.

32 S. Burt, Essential Oils: Their Antibacterial Properties and Potential Applications in Foods - A Review, Int. J. Food Microbiol., 2004, 94, 223-253.

33 S. Shreaz, W. A. Wani, J. M. Behbehani, V. Raja, M. Irshad, M. Karched, I. Ali, W. A. Siddiqi and L. T. Hun, Cinnamaldehyde and Its Derivatives, a Novel Class of Antifungal Agents, Fitoterapia, 2016, 112, 116-131.

34 F. Ling, C. Jiang, G. Liu, M. Li and G. Wang, Anthelmintic Efficacy of Cinnamaldehyde and Cinnamic Acid from Cortex Cinnamon Essential Oil against Dactylogyrus intermedius, Parasitology, 2015, 142, 1744-1750.

35 X. C. Liu, J. Cheng, N. N. Zhao and Z. L. Liu, Insecticidal Activity of Essential Oil of Cinnamomum cassia and Its Main Constituent, Trans-Cinnamaldehyde, against the Booklice, Liposcelis bostrychophila, Trop. J. Pharm. Res., 2014, 13, 1697-1702.

36 K. Hayashi, N. Imanishi, Y. Kashiwayama, A. Kawano, K. Terasawa, Y. Shimada and H. Ochiai, Inhibitory Effect of Cinnamaldehyde, Derived from Cinnamomi Cortex, on the Growth of Influenza $\mathrm{A} / \mathrm{PR} / 8$ Virus in vitro and in vivo, Antiviral Res., 2007, 74, 1-8.

37 H. Ka, H. J. Park, H. J. Jung, J. W. Choi, K. S. Cho, J. Ha and K. T. Lee, Cinnamaldehyde Induces Apoptosis by ROS-Mediated Mitochondrial Permeability Transition in Human Promyelocytic Leukemia HL-60 Cells, Cancer Lett., 2003, 196, 143-152.

38 W. Zhang, Y. C. Xu, F. J. Guo, Y. Meng and M. L. Li, AntiDiabetic Effects of Cinnamaldehyde and Berberine and Their Impacts on Retinol-Binding Protein 4 Expression in Rats with Type 2 Diabetes Mellitus, Chin. Med. J., 2008, 121, 2124-2128.

39 X. Yuan, L. Han, P. Fu, H. Zeng, C. Lv, W. Chang, R. S. Runyon, M. Ishii, L. Han, K. Liu, T. Fan, W. Zhang and R. Liu, Cinnamaldehyde Accelerates Wound Healing by Promoting Angiogenesis via Up-Regulation of PI3K and MAPK Signalling Pathways, Lab. Invest., 2018, 98, 783-793.

40 M. Friedman, Chemistry, Antimicrobial Mechanisms, and Antibiotic Activities of Cinnamaldehyde against Pathogenic Bacteria in Animal Feeds and Human Foods, J. Agric. Food Chem., 2017, 65, 10406-10423.

41 S. Shen, T. Zhang, Y. Yuan, S. Lin, J. Xu and H. Ye, Effects of Cinnamaldehyde on Escherichia coli and Staphylococcus aureus Membrane, Food Control, 2015, 47, 196-202.

42 R. Moghimi, A. Aliahmadi and H. Rafati, Ultrasonic Nanoemulsification of Food Grade Trans-Cinnamaldehyde: 1,8Cineol and Investigation of the Mechanism of Antibacterial Activity, Ultrason. Sonochem., 2017, 35, 415-421.

43 S. W. Nowotarska, K. Nowotarski, I. R. Grant, C. T. Elliott, M. Friedman and C. Situ, Mechanisms of Antimicrobial
Action of Cinnamon and Oregano Oils, Cinnamaldehyde, Carvacrol, 2,5-Dihydroxybenzaldehyde, and 2-Hydroxy-5Methoxybenzaldehyde against Mycobacterium avium subsp. paratuberculosis (Map), Foods., 2017, 6, 72.

44 T. F. He, L. H. Wang, D. B. Niu, Q. H. Wen and X. A. Zeng, Cinnamaldehyde Inhibit Escherichia coli Associated with Membrane Disruption and Oxidative Damage, Arch. Microbiol., 2019, 201, 451-458.

45 C. Han, J. Wang, Y. Li, F. Lu and Y. Cui, AntimicrobialCoated Polypropylene Films with Polyvinyl Alcohol in Packaging of Fresh Beef, Meat Sci., 2014, 96, 901-907.

46 M. Ramos, A. Jiménez, M. Peltzer and M. C. Garrigós, Characterization and Antimicrobial Activity Studies of Polypropylene Films with Carvacrol and Thymol for Active Packaging, J. Food Eng., 2012, 109, 513-519.

47 U. Nayanathara, N. Kottegoda, I. C. Perera and T. K. Mudiyanselage, Synthesis, Photodegradable and Antibacterial Properties of Polystyrene-Cinnamaldehyde Copolymer Film, Polym. Degrad. Stab., 2018, 155, 195-207.

48 N. Sanla-Ead, A. Jangchud, V. Chonhenchob and P. Suppakul, Antimicrobial Activity of Cinnamaldehyde and Eugenol and Their Activity after Incorporation into Cellulose-Based Packaging Films, Packag. Technol. Sci., 2012, 25, 7-17.

49 M. H. Hosseini, S. H. Razavi and M. A. Mousavi, Antimicrobial, Physical and Mechanical Properties of Chitosan-Based Films Incorporated with Thyme, Clove and Cinnamon Essential Oils, J. Food Process. Preserv., 2009, 33, 727-743.

50 S. Ravishankar, L. Zhu, C. W. Olsen, T. H. McHugh and M. Friedman, Edible Apple Film Wraps Containing Plant Antimicrobials Inactivate Foodborne Pathogens on Meat and Poultry Products, J. Food Sci., 2009, 74, M440-M445.

51 G. R. Gamage, H. J. Park and K. M. Kim, Effectiveness of Antimicrobial Coated Oriented Polypropylene/Polyethylene Films in Sprout Packaging, Food Res. Int., 2009, 42, 832-839.

52 F. A. Lopes, N. De Fátima Ferreira Soares, C. De Cássia Pires Lopes, W. A. Da Silva, J. C. B. Júnior and E. A. A. Medeiros, Conservation of Bakery Products through Cinnamaldehyde Antimicrobial Films, Packag. Technol. Sci., 2014, 27, 293-302.

53 H. J. Huang and X. Z. Yuan, Recent Progress in the Direct Liquefaction of Typical Biomass, Prog. Energy Combust. Sci., 2015, 49, 59-80.

54 A. Torres, J. Romero, A. Macan, A. Guarda and M. J. Galotto, Near Critical and Supercritical Impregnation and Kinetic Release of Thymol in LLDPE Films Used for Food Packaging, J. Supercrit. Fluids, 2014, 85, 41-48.

55 A. D. M. Mathekga and J. J. M. Meyer, Antibacterial Activity of South African Helichrysum Species, S. Afr. J. Bot., 1998, 64, 293-295.

56 P. V. Gersbach, The Essential Oil Secretory Structures of Prostanthera ovalifolia (Lamiaceae), Ann. Bot., 2002, 89, 255-260.

57 S. S. Voo, H. D. Grimes and B. M. Lange, Assessing the Biosynthetic Capabilities of Secretory Glands in Citrus Peel, Plant Physiol., 2012, 159, 81-94.

58 J. Kucinska-Lipka, I. Gubanska, A. Lewandowska, A. Terebieniec, A. Przybytek and H. Cieśliński, Antibacterial Polyurethanes, Modified with Cinnamaldehyde, as Potential 
Materials for Fabrication of Wound Dressings, Polym. Bull, 2019, 76, 2725-2742.

59 D. R. Dreyer, D. J. Miller, B. D. Freeman, D. R. Paul and C. W. Bielawski, Elucidating the Structure of Poly(Dopamine), Langmuir, 2012, 28, 6428-6435.

60 A. Mohammed, H. Aliyu and N. Taher, Synthesis and Characterization of Some Cinnamaldehyde Schiff Base Complexes, Rafidain J. Sci., 2008, 19, 45-51.

61 S. Konar, D. Samanta, S. Mandal, S. Das, M. K. Mahto, M. Shaw, M. Mandal and A. Pathak, Selective and Sensitive Detection of Cinnamaldehyde by Nitrogen and Sulphur CoDoped Carbon Dots: A Detailed Systematic Study, RSC Adv., 2018, 8, 42361-42373.

62 K. Guo and Y. Chen, Simple and Rapid Detection of Aromatic Amines Using a Thin Layer Chromatography Plate, Anal. Methods, 2010, 2, 1156-1159.

63 J. H. Lin, C. J. Yu, Y. C. Yang and W. L. Tseng, Formation of Fluorescent Polydopamine Dots from Hydroxyl RadicalInduced Degradation of Polydopamine Nanoparticles, Phys. Chem. Chem. Phys., 2015, 17, 15124-15130.

64 K. K. Singh and C. S. Mathela, Synthesis, Characterization and in Vitro Antibacterial Activity of Cinnamyl Amine Derivatives, Indian J. Chem., 2014, 53, 907-912.

65 M. E. I. Badawy and E. I. Rabea, Synthesis and Structure-Activity Relationship of $\mathrm{N}$-(Cinnamyl) Chitosan Analogs as Antimicrobial Agents, Int. J. Biol. Macromol., 2013, 57, 185-192.

66 N. F. Della Vecchia, R. Avolio, M. Alfè, M. E. Errico, A. Napolitano and M. D'Ischia, Building-Block Diversity in Polydopamine Underpins a Multifunctional EumelaninType Platform Tunable through a Quinone Control Point, Adv. Funct. Mater., 2013, 23, 1331-1340.

67 N. F. Della Vecchia, A. Luchini, A. Napolitano, G. Derrico, G. Vitiello, N. Szekely, M. Dischia and L. Paduano, Tris Buffer Modulates Polydopamine Growth, Aggregation, and Paramagnetic Properties, Langmuir, 2014, 30, 9811-9818.

68 Protocol for the Evaluation of Bactericidal Activity of Hard, Non-porous Copper/Copper-Alloy Surfaces. US Environmental Protection Agency Office. 3rd February 2015.

69 A. Kasprzak, M. Popławska, M. Bystrzejewski, O. Łabędź and I. P. Grudziński, Conjugation of Polyethyleneimine and Its Derivatives to Carbon-Encapsulated Iron Nanoparticles, RSC Adv., 2015, 5, 85556-85567.

70 H. Yoshitake, E. Koiso, H. Horie and H. Yoshimura, Polyamine-Functionalized Mesoporous Silicas: Preparation, Structural Analysis and Oxyanion Adsorption, Microporous Mesoporous Mater., 2005, 85, 183-194.

71 S. M. Lee, K. S. Sim and K. M. Lo, Synthesis, Characterization and Biological Studies of Diorganotin(Iv) Complexes with Tris[(Hydroxymethyl)Aminomethane] Schiff Bases, Inorg. Chim. Acta, 2015, 429, 195-208.

72 R. F. Martínez, M. Úvalos, R. Babiano, P. Cintas, J. L. Jiménez, M. E. Light and J. C. Palacios, Schiff Bases from TRIS and Ortho-Hydroxyarenecarbaldehydes: Structures and Tautomeric Equilibria in the Solid State and in Solution, Eur. J. Org. Chem., 2011, 3137-3145.

73 M. Y. Lim, Y. S. Choi, J. Kim, K. Kim, H. Shin, J. J. Kim, D. M. Shin and J. C. Lee, Cross-Linked Graphene Oxide Membrane Having High Ion Selectivity and Antibacterial Activity Prepared Using Tannic Acid-Functionalized Graphene Oxide and Polyethyleneimine, J. Membr. Sci., 2017, 521, 1-9.

74 M. Gürsoy, M. T. Harris, J. O. Downing, S. N. BarrientosPalomo, A. Carletto, A. E. Yaprak, M. Karaman and J. P. S. Badyal, Bioinspired Fog Capture and Channel Mechanism Based on the Arid Climate Plant Salsola crassa, Colloids Surf., A, 2017, 529, 195-202.

75 T. Sun, Z. J. Li, H. G. Wang, D. Bao, F. L. Meng and X. B. Zhang, A Biodegradable Polydopamine-Derived Electrode Material for High-Capacity and Long-Life Lithium-Ion and Sodium-Ion Batteries, Angew. Chem., Int. Ed., 2016, 55, 10662-10666.

76 K. T. Chung, T. Y. Wong, C. I. Wei, Y. W. Huang and Y. Lin, Tannins and Human Health: A Review, Crit. Rev. Food Sci. Nutr., 1998, 38, 421-464.

77 M. Shin, J. H. Ryu, J. P. Park, K. Kim, J. W. Yang and H. Lee, DNA/Tannic Acid Hybrid Gel Exhibiting Biodegradability, Extensibility, Tissue Adhesiveness, and Hemostatic Ability, Adv. Funct. Mater., 2015, 25, 1270-1278.

78 T. B. Adams, S. M. Cohen, J. Doull, V. J. Feron, J. I. Goodman, L. J. Marnett, I. C. Munro, P. S. Portoghese, R. L. Smith, W. J. Waddell and B. M. Wagner, The FEMA GRAS Assessment of Cinnamyl Derivatives Used as Flavor Ingredients, Food Chem. Toxicol., 2004, 42, 157-185.

79 A. Aksoy and S. Kaplan, Production and Performance Analysis of an Antibacterial Foot Sweat Pad, Fibers Polym., 2013, 14, 316-323.

80 S. Kaplan, S. Pulan and S. Ulusoy, Objective and Subjective Performance Evaluations of Wet Wipes Including Herbal Components, J. Ind. Text., 2018, 47, 1959-1978.

81 C. H. Ho, E. K. Odermatt, I. Berndt and J. C. Tiller, LongTerm Active Antimicrobial Coatings for Surgical Sutures Based on Silver Nanoparticles and Hyperbranched Polylysine, J. Biomater. Sci., Polym. Ed., 2013, 24, 1589-1600.

82 C. P. Fik, S. Konieczny, D. H. Pashley, C. J. Waschinski, R. S. Ladisch, U. Salz, T. Bock and J. C. Tiller, Telechelic Poly(2-oxazoline)s with a Biocidal and a Polymerizable Terminal as Collagenase Inhibiting Additive for LongTerm Active Antimicrobial Dental Materials, Macromol. Biosci., 2014, 14, 1569-1579.

83 T. Faunce and A. Watal, Nanosilver and Global Public Health: International Regulatory Issues, Nanomedicine, 2010, 5, 617-632.

84 P. I. Hora, S. G. Pati, P. J. McNamara and W. A. Arnold, Increased Use of Quaternary Ammonium Compounds During the SARS-CoV-2 Pandemic and Beyond: Consideration of Environmental Implications, Environ. Sci. Technol. Lett., 2020, 7, 622-631. 